\title{
Inhibitory mechanisms of low concentrations of oxidized low-density lipoprotein on platelet aggregation
}

\author{
Duen-Suey Chou ${ }^{1}$, Chih-Hsiang Chan ${ }^{3}$, George Hsiao ${ }^{2}$, Ming-Yi Shen ${ }^{1}$, Yan-Jyu Tsai ${ }^{2}$, \\ Tzeng-Fu Chen ${ }^{2} \&$ Joen-Rong Sheu ${ }^{1,2, *}$ \\ ${ }^{1}$ Graduate Institute of Medical Sciences, Taipei Medical University, Taipei, Taiwan, ROC; ${ }^{2}$ Graduate \\ Institute of Pharmacology, Taipei Medical University, Taipei, Taiwan, ROC; ${ }^{3}$ Division of Cardiology, Min- \\ Sheng Hospital, Taoyuan, Taiwan, ROC
}

Received 12 April 2005; accepted 11 October 2005

(C) 2005 National Science Council, Taipei

Key words: cyclic AMP, $\mathrm{Na}^{+} / \mathrm{H}^{+}$exchanger, oxLDL, protein kinase $\mathrm{C}$, vasodilator-stimulated phosphoprotein

\section{Summary}

The intracellular mechanisms underlying oxidized low-density lipoprotein (oxLDL)-signaling pathways in platelets are not yet completely understood. Therefore, the aim of this study was to further examine the effects of oxLDL in prevention of platelet aggregation. In this study, oxLDL concentration-dependently $(40-120 \mu \mathrm{g} / \mathrm{ml})$ inhibited platelet aggregation in human platelet-rich plasma stimulated by agonists. Moreover, oxLDL (40 and $80 \mu \mathrm{g} / \mathrm{ml}$ ) markedly decreased the fluorescence intensity of platelet membranes tagged with diphenylhexatriene. Rapid phosphorylation of a protein of $M r$ 47,000 (P47), a marker of protein kinase $\mathrm{C}$ activation, was triggered by $\mathrm{PDBu}(150 \mathrm{nM})$. This phosphorylation was markedly inhibited by oxLDL ( 40 and $80 \mu \mathrm{g} / \mathrm{ml}$ ) in phosphorus-32-labeled platelets. In addition, oxLDL (40 and $80 \mu \mathrm{g} / \mathrm{ml}$ ) markedly increased levels of cyclic AMP and cyclic AMP-induced vasodilator-stimulated phosphoprotein (VASP) Ser ${ }^{157}$ phosphorylation. The thrombin-evoked increase in $\mathrm{pHi}$ was inhibited in the presence of oxLDL ( 40 and $80 \mu \mathrm{g} / \mathrm{ml}$ ). These results indicate that the antiplatelet activity of oxLDL may involve the following pathways. (1) oxLDL may initially induce conformational changes in platelet membranes, leading to inhibition of the activation of protein kinase $\mathrm{C}$, followed by inhibition of P47 protein phosphorylation, and intracellular $\mathrm{Ca}^{2+}$ mobilization. (2) oxLDL also activated formation of cyclic AMP and cyclic AMP-induced VASP Ser ${ }^{157}$ phosphorylation, resulting in inhibition of the $\mathrm{Na}^{+} / \mathrm{H}^{+}$exchanger; this leads to reduced intracellular $\mathrm{Ca}^{2+}$ mobilization, and ultimately to inhibition of platelet aggregation. This study further provides new insights concerning the effects of low concentrations of oxLDL on platelet aggregation.

\section{Introduction}

Plasma lipoproteins, particularly low-density lipoprotein (LDL), are the source of the lipid that accumulates in atherosclerotic lesions [1]. Oxidative modification dramatically changes the biological

*To whom correspondence should be addressed. Fax +886-227390450, E-mail: sheujr@tmu.edu.tw properties of LDL, converting it into a form that is both atherogenic and prothrombotic [1]. The oxidation theory of atherosclerosis proposes that formation of oxidized low-density lipoprotein (oxLDL) in the subendothelial space of artery walls represents a causative event for atherogenesis. Evidence of oxidized lipoproteins has been detected in atherosclerotic lesions [2], and oxLDL exhibits various proatherogenic activities [3]. 
Platelets interact with plasma lipoprotein as well as with arterial wall macrophages that play an important role in atherogenesis [4]. Plasma lipoproteins have been shown to affect platelet activity in vitro and in vivo. The susceptibility of platelets to aggregation in vitro upon stimulation by aggregating agents, such as ADP and collagen, has been shown to increase in most, but not all, studies of platelet-rich plasma (PRP) from hypercholesterolemic individuals [5].

Oxidation of LDL may be one of the main factors involved in the initial development of atherosclerotic lesions [2]. LDL can be oxidized within the arterial wall by macrophages; this process, which favors accumulation of LDL in the intima of the arterial wall, is thought to be a possible explanation for the progression of arteriosclerotic lesions. Endothelial cells also induce oxLDL formation, but in turn may be damaged by oxLDL [2]. LDL has been suggested to have platelet-activating properties such as decreasing the threshold for stimulation by aggregation agents and inducing platelet aggregation [6, 7]. However, evidence regarding the induction of platelet activation by LDL is controversial. Several studies have reported inhibition of agonistinduced platelet aggregation by native LDL (nLDL) [8, 9]. In others, platelet-activating effects of either lower $\mathrm{nLDL}(10-50 \mu \mathrm{g} / \mathrm{ml})[10]$ or higher concentrations of LDL (more than 1-2 mg/ml) have been described [6]. Furthermore, plateletactivating activity was found to reside in oxLDL rather than in nLDL [11]. oxLDL plays an important role in the pathogenesis of atherosclerosis; it has also been reported to enhance platelet activation in some [7, 12], but not all studies [13, 14]. Vlasova et al. [14] found that highly oxidized LDL not only failed to activate platelet aggregation, but also inhibited ADP-induced aggregation. However, they also found that mildly oxidized LDL diminished the time-dependent decrease in platelet aggregability in platelet-rich plasma [15]. Such discrepancies among reported oxLDL-platelet interactions may depend on methodological variations in the isolation, oxidization, and dosage of lipoproteins employed, which might result in non-homogeneous oxidation [9].

In our previous studies, we found that oxLDL (LDL oxidized with copper), at lower concentrations $(40-80 \mu \mathrm{g} / \mathrm{ml})$, significantly inhibited agonist-induced platelet aggregation [16]. In that study, we found that the $12 \mathrm{~h}$ - and $24 \mathrm{~h}$-oxLDL, but not nLDL, concentration-dependently (20$100 \mu \mathrm{g} / \mathrm{ml})$ inhibited platelet aggregation stimulated by collagen $(1 \mu \mathrm{g} / \mathrm{ml})$ and $\mathrm{AA}(60 \mu M)$ in human platelet suspensions. The $\mathrm{IC}_{50}$ values of the $12 \mathrm{~h}$ - and $24 \mathrm{~h}$-oxLDL for platelet aggregation induced by collagen were estimated to be about $46.3 \pm 1.1$ and $55.2 \pm 1.0 \mu \mathrm{g} / \mathrm{ml}$, respectively [16] We suggested that the inhibitory effect of oxLDL may induce radical-radical termination reactions by oxLDL-derived lipid radical interactions with free radicals (such as hydroxyl radicals) released from activated platelets, with a resultant lowering of intracellular $\mathrm{Ca}^{2+}$ mobilization, followed by inhibition of thromboxane $\mathrm{A}_{2}$ formation, thereby leading to increased cyclic AMP formation, and finally inhibited platelet aggregation [16]. In that study, we partially resolved the mechanisms of oxLDL on platelet aggregation, however detailed intracellular mechanisms underlying oxLDLplatelet interaction are still not yet completely understood. We therefore further examined the effect of oxLDL in human platelets, and utilized the findings to characterize the mechanisms involved in oxLDL-platelet interactions.

\section{Materials and methods}

\section{Materials}

Collagen (type I, bovine Achilles tendon), arachidonic acid, prostaglandin $\mathrm{E}_{1}\left(\mathrm{PGE}_{1}\right)$, nigericin, sodium citrate, phorbol-12, 13-dibutyrate (PDBu), apyrase, diphenylhexatriene (DPH), and heparin were purchased from Sigma Chem. (St. Louis, MO). Fura 2-AM, BCECF-AM, and fluorescein isothiocyanate (FITC) were purchased from Molecular Probe (Eugene, OR). Trimeresurus flavoviridis venom was purchased from Latoxan (Rosans, France).

\section{Preparation of human platelet suspensions}

Human platelet suspensions were prepared as previously described [17]. In this study, human volunteers provided informed consent. In brief, blood was collected from healthy human volunteers who had taken no medicine during the preceding 2 weeks, and was mixed with acid/ citrate/glucose. After centrifugation at $120 \times g$ 
for $10 \mathrm{~min}$, the supernatant (platelet-rich plasma; PRP) was supplemented with $\operatorname{PGE}_{1}(0.5 \mu \mathrm{M})$ and heparin $(6.4 \mathrm{IU} / \mathrm{ml})$, then incubated for $10 \mathrm{~min}$ at $30{ }^{\circ} \mathrm{C}$ and centrifuged at $500 \times g$ for $10 \mathrm{~min}$. The washed platelets were finally suspended in Tyrode's solution containing bovine serum albumin (BSA) $(3.5 \mathrm{mg} / \mathrm{ml})$ and adjusted to a concentration of $4.5 \times 10^{8}$ platelets $/ \mathrm{ml}$. The final concentration of $\mathrm{Ca}^{2+}$ in Tyrode's solution was $1 \mathrm{mM}$.

\section{Isolation of human plasma $L D L$}

Human LDL (at a density of 1.109-1.063) was isolated from fresh plasma of fasted normolipidemic human volunteers and collected in EDTA $(2 \mathrm{mM})$ by sequential density gradient ultracentrifugation as described by Dousset et al. [18]. In brief, the plasma density was adjusted to $1.02 \mathrm{~g} / \mathrm{ml}$ using a $\mathrm{NaCl}-\mathrm{KBr}$ solution for immediate separation of very low density lipoproteins (VLDLs) and intermediate-density lipoproteins (IDLs), and then adjusted to $1.063 \mathrm{~g} / \mathrm{ml}$ for separation of LDL. The LDL was further purified by resuspension in the appropriate $\mathrm{NaCl}-\mathrm{KBr}$ solution $(1.063 \mathrm{~g} / \mathrm{ml})$ and ultracentrifuged. The LDL was then dialyzed for $24 \mathrm{~h}$ at $4{ }^{\circ} \mathrm{C}$ against three changes of nitrogen gas with $0.02 \mathrm{M}$ Tris buffer in order to remove the EDTA and KBr. After dialysis, LDL was stored for not more than 7 days under nitrogen at $4{ }^{\circ} \mathrm{C}$ in the dark. Total protein concentration was measured by the Lowry method using BSA as the standard [18].

\section{Oxidation of $L D L$}

After adjustment of the LDL concentration to $0.5 \mathrm{mg} / \mathrm{ml}$ (expressed as the total LDL concentration), lipoprotein preparations were dialyzed against 100 volumes of $10 \mathrm{mM}$ sodium phosphate buffer (containing $150 \mathrm{mM} \mathrm{NaCl}, \mathrm{pH} 7.4$ ) for $18 \mathrm{~h}$ at $4{ }^{\circ} \mathrm{C}$ in the dark. Oxidation was initiated by addition of $\mathrm{CuSO}_{4}(5 \mu \mathrm{M})$ for $24 \mathrm{~h}$ at $37^{\circ} \mathrm{C}$, and was stopped after the addition of EDTA $(20 \mu \mathrm{M})$. Before the functional studies, oxLDL was filtered through a Sephadex PD-10 column (Pharmacia) in order to remove the EDTA and copper, and was reconcentrated at $4{ }^{\circ} \mathrm{C}$ using Centricon 3000 filters (Amicon, Bedford, MA) according to the manufacturer's instructions. Oxidation was confirmed by the thiobarbituric acid-reactive substance (TBARS) assay [19]. Tetramethoxypropane was used as a standard, and the results were expressed as nanomoles of malondialdehyde (MDA) equivalents per milligram protein of LDL. The extent of aldehyde-modified lysine in oxidized LDL (adjusted to $0.1 \mathrm{mg}$ LDL protein $/ \mathrm{ml}$ ) was monitored by determining the fluorescence intensity (excitation at $350 \mathrm{~nm}$ and emission at $420 \mathrm{~nm}$ ) [20]. The oxLDL was used in all of the functional studies within $48 \mathrm{~h}$ of preparation.

\section{Platelet aggregation}

The turbidimetric method was applied to measure platelet aggregation [17], using a Lumi-Aggregometer (Payton, Canada). Platelet-rich plasma (PRP; $4.5 \times 10^{8}$ platelets $/ \mathrm{ml}, 0.4 \mathrm{ml}$ ) was prewarmed to $37^{\circ} \mathrm{C}$ for $2 \mathrm{~min}$ in a silicone-treated glass cuvette. oxLDL $(40-120 \mu \mathrm{g} / \mathrm{ml})$ was added 3 min before the addition of agonists. The reaction was allowed to proceed for at least $6 \mathrm{~min}$, and the extent of aggregation was expressed in light-transmission units.

Analysis of the platelet surface glycoprotein IIb/IIIa complex by flow cytometry

Triflavin, a specific fibrinogen receptor (glycoprotein IIb/IIIa complex; $\alpha_{\mathrm{IIb}} \beta_{3}$ integrin) antagonist, was prepared as previously described [21]. Fluorescence-conjugated triflavin was also prepared as previously described [21]. The final concentration of FITC-conjugated triflavin was adjusted to $1 \mathrm{mg} / \mathrm{ml}$. Aliquots of platelet suspensions $\left(4.5 \times 10^{8} / \mathrm{ml}\right)$ as described above were preincubated with oxLDL (40 and $80 \mu \mathrm{g} / \mathrm{ml}$ ) for $3 \mathrm{~min}$, followed by the addition of $2 \mu \mathrm{l}$ FITC-triflavin. The suspensions were then incubated for another $5 \mathrm{~min}$, and the volume was adjusted to $1 \mathrm{ml} /$ tube with Tyrode's solution. The suspensions were then assayed for fluorescein-labeled platelets with a flow cytometer (Becton Dickinson, FACScan Syst., San Jose, CA). Data were collected from 50,000 platelets per experimental group. All experiments were repeated at least four times to ensure reproducibility.

\section{Measurement of membrane fluidity by fluorescent} probe

The intensity of fluorescence in human platelets was measured as described previously [22]. Briefly, 
platelets $\left(4.5 \times 10^{8} / \mathrm{ml}\right)$ were preincubated with oxLDL (40 and $80 \mu \mathrm{g} / \mathrm{ml}$ ) for $3 \mathrm{~min}$ followed by the addition of $0.5 \mu \mathrm{M}$ of a diphenylhexatriene (DPH) solution for another $6 \mathrm{~min}$. The relative fluorescence intensity of platelets was measured in a fluorescence spectrophotometer (Hitachi F4500, Tokyo, Japan) at $37^{\circ} \mathrm{C}$.

\section{Determination of lactate dehydrogenase}

Lactate dehydrogenase (LDH) was measured according to previously described methods [23]. Platelets $\left(4.5 \times 10^{8} / \mathrm{ml}\right)$ were preincubated with oxLDL (40 and $80 \mu \mathrm{g} / \mathrm{ml}$ ) for $30 \mathrm{~min}$, followed by centrifugation at $15,000 \times g$ for $5 \mathrm{~min}$. An aliquot of supernatant was incubated with phosphate buffer containing $0.2 \mathrm{mg} \beta-\mathrm{NADH}$ for $20 \mathrm{~min}$. Thereafter, $100 \mu \mathrm{l}$ of pyruvate solution was added, and the absorbance wavelength was read at $334 \mathrm{~nm}$ using a UV-visible recording spectrophotometer (UV-160; Shimazu, Kyoto, Japan). A maximal value of LDH was constructed from sonicated platelets.

\section{Measurement of Protein Kinase C (PKC) activation}

Washed human platelets $\left(2 \times 10^{9} / \mathrm{ml}\right)$ were incubated for $60 \mathrm{~min}$ at $37^{\circ} \mathrm{C}$ with phosphorus-32 $(0.5 \mathrm{mCi} / \mathrm{ml})$. Platelet suspensions were next washed twice with Tris-saline buffer. The $\left[{ }^{32} \mathrm{P}\right]-$ labeled platelets were preincubated with oxLDL (40 and $80 \mu \mathrm{g} / \mathrm{ml}$ ) in an aggregometer at $37^{\circ} \mathrm{C}$ for $3 \mathrm{~min}$, then PDBu (150 nM) was added for $1 \mathrm{~min}$ to trigger PKC activation. Activation was terminated by the addition of Laemmli sample buffer, and analyzed by electrophoresis $(12.5 \%$; wt $/ \mathrm{vol})$ as described previously [24]. The gels were dried, and the relative intensities of the radioactive bands were analyzed using a Bio-imaging analyzer system (FAL2000, Fuji, Tokyo, Japan), and expressed as $\mathrm{PSL} / \mathrm{mm}^{2}$ (PSL, photostimulated luminescence).

Western blot analysis of vasodilator-stimulated phosphoprotein (VASP) phosphorylation

The method of Li et al. [25] was followed. In brief, platelet lysates were analyzed by SDS-PAGE gel $(10 \%)$ and electrotransferred to PVDF membranes. Membranes were blocked with 5\% nonfat dry milk in Tris (tris(hydroxymethyl)-aminometh- ane)-buffered saline (TBS, pH7.5), incubated with the monoclonal antibody 5C6 (CALBIOCHEM), specific for the phosphorylated $\mathrm{Ser}^{157}$ site of VASP $(0.1 \mu \mathrm{g} / \mathrm{ml})$. After three washes in TBS containing $0.05 \%$ Tween 20 , the membrane was incubated with peroxidase-conjugated goat anti-mouse $\operatorname{IgG}$ (Amersham) for $2 \mathrm{~h}$. The band with peroxidase activity was detected by enhanced chemiluminescence detection reagents $\left(\mathrm{ECL}^{+}\right.$system; Amersham). Densitometric analysis of specific bands was performed with a Photo-Print Digital Imaging System (IP-008-SD) with analytical software (Bio1Dlight, V 2000).

\section{Platelet pHi measurement}

Platelet pHi was measured with the fluorescent probe, BCECF-AM, according to a previously described method [26]. Washed platelets were incubated with $5 \mu \mathrm{M}$ BCECF-AM at $37^{\circ} \mathrm{C}$ for $30 \mathrm{~min}$ in a Hepes-buffered solution (HBS, $\mathrm{pH}$ 7.4) and then centrifuged at $450 \times g$ for $8 \mathrm{~min}$. Washed pellets were finally suspended in buffer and adjusted to $4.5 \times 10^{8} / \mathrm{ml}$. Leukocyte contamination was less than $0.01 \%$. Aliquots of this platelet suspension $(50 \mu \mathrm{l})$ were transferred to a cuvette containing $2 \mathrm{ml}$ HBS in a dual-excitation wavelength spectrofluorometer (CAF 110, Jasco, Japan). Fluorescence signals for BCECF-AM were recorded at 430- and 490-nm excitation wavelengths with an emission wavelength of $530 \mathrm{~nm}$ (5$\mathrm{nm}$ slit). The background fluorescence of platelets was subtracted from each reading. Calibration was carried out after diluting the BCECF-loaded platelets in a high- $\mathrm{K}^{+}$buffer $(120 \mathrm{mM} \mathrm{KCl}$, $30 \mathrm{mM} \mathrm{NaCl}, 1 \mathrm{mM} \mathrm{MgSO}_{4}$, and $5 \mathrm{mM}$ glucose) in the presence of nigericin $(0.2 \mathrm{mg} / \mathrm{ml})$, as described by Horne et al. [27]. In all experiments, platelets were stimulated by thrombin $(1 \mathrm{U} / \mathrm{ml})$ to trigger the $\mathrm{Na}^{+} / \mathrm{H}^{+}$exchanger.

\section{Statistical analysis}

Experimental results are expressed as the mean \pm SEM and are accompanied by the number of observations. Data were assessed using analysis of variance (ANOVA). If this analysis indicated significant differences among the group means, then each group was compared using the Newman-Keuls method. A $P$ value of $<0.05$ was considered statistically significant. 


\section{Results}

Effect of $O x L D L$ on platelet aggregation in platelet-rich plasma

The oxLDL preparation was oxidized and concentrated to contain $51.4 \pm 1.8 \mathrm{nmol}$ of $\mathrm{MDA} / \mathrm{mg}$ protein. The extent of aldehyde-modified lysine in oxLDL was $13.1 \pm 1.4$. In our previous study [16], we demonstrated that oxLDL, but not native LDL
(nLDL), concentration-dependently (20-100 $\mu \mathrm{g} /$ $\mathrm{ml})$ inhibited platelet aggregation stimulated by collagen $(1 \mu \mathrm{g} / \mathrm{ml})$ and arachidonic acid $(60 \mu \mathrm{M})$ in washed human platelets [16]. The $\mathrm{IC}_{50}$ value of the oxLDL for platelet aggregation induced by collagen was estimated to be $55.2 \pm 1.0 \mu \mathrm{g} / \mathrm{ml}$ [16]. In this study, we further examined whether oxLDL also exhibits a similar inhibitory activity in PRP. As shown in Figure 1, oxLDL $(40-120 \mu \mathrm{g} / \mathrm{ml})$ concentration-dependently inhibited platelet
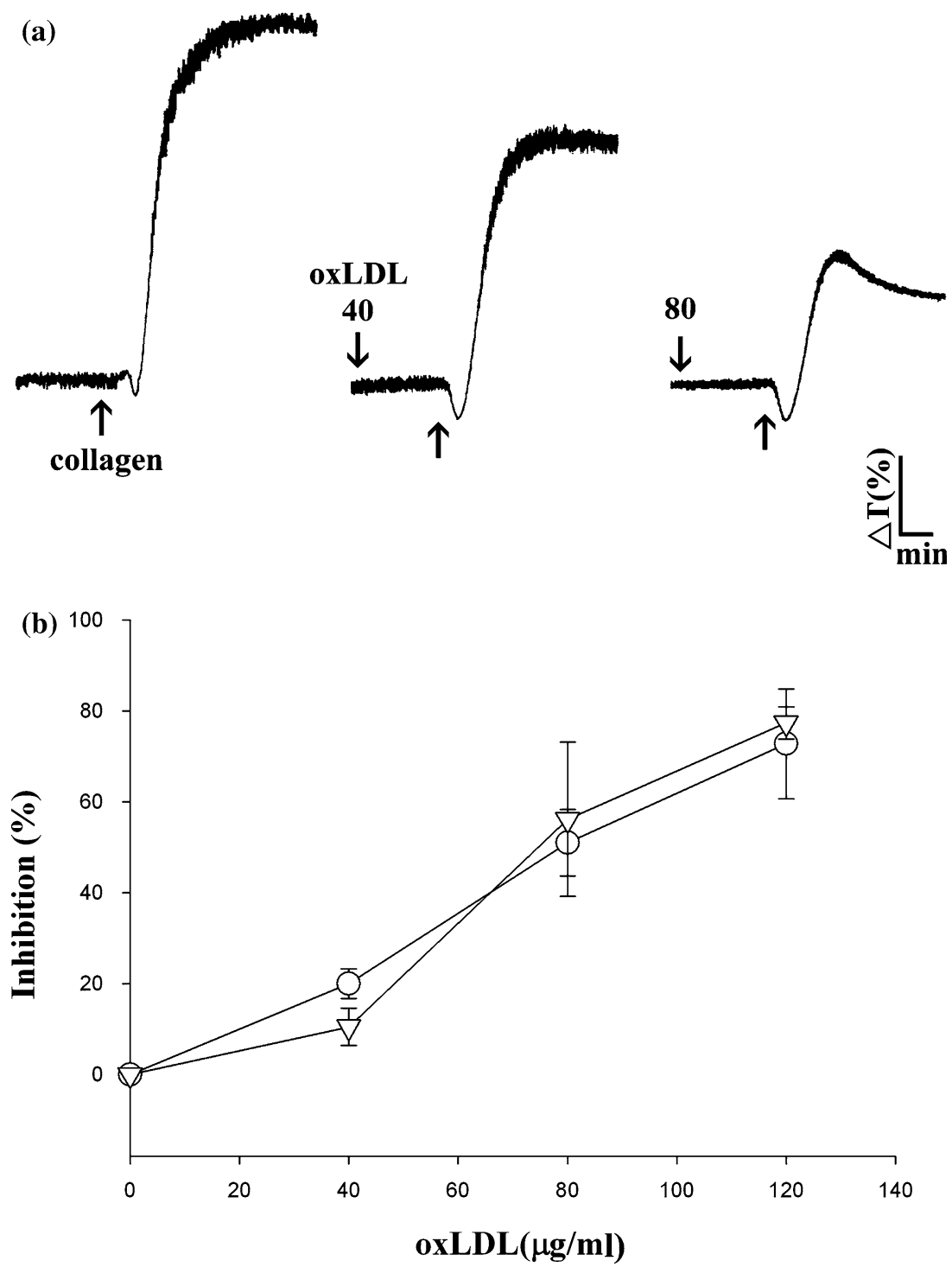

Figure 1. Effect of oxLDL in agonists-induced platelet aggregation in human platelet-rich plasma. (a) Tracing curves of oxLDL on collagen ( $1 \mu \mathrm{g} / \mathrm{ml})$-induced aggregation and (b) concentration-inhibition curves of oxLDL on collagen $(1 \mu \mathrm{g} / \mathrm{ml}, \bigcirc)$-, and arachidonic acid $(60 \mu \mathrm{M}, \nabla)$-induced platelet aggregation in human platelet-rich plasma (PRP). Platelets were preincubated with oxLDL $(40-120 \mu \mathrm{g} / \mathrm{ml})$ for $3 \mathrm{~min}$, followed by the addition of collagen and arachidonic acid to trigger platelet aggregation. Data are presented as a percentage of the control (means \pm SEM, $n=4$ ). 
aggregation stimulated by collagen $(1 \mu \mathrm{g} / \mathrm{ml})$ and arachidonic acid $(60 \mu \mathrm{M})$ in human PRP. The $\mathrm{IC}_{50}$ value for platelet aggregation stimulated by collagen in PRP was about $83.2 \pm 9.5 \mu \mathrm{g} / \mathrm{ml}$ (Figure $1 \mathrm{~b}$ ), a little higher than that of the $\mathrm{IC}_{50}$ value obtained in washed platelets [16], indicating that oxLDL seems to be bound by plasma protein, thus lowers its antiplatelet activity. In addition, the solvent control (Tyrode's solution) did not significantly affect the platelet aggregation stimulated by collagen $(1 \mu \mathrm{g} / \mathrm{ml})$ in PRP (data not shown). In the following experiments, we used collagen as an agonist to further explore its inhibitory mechanisms on platelet aggregation.

\section{Effect of $O x L D L$ on collagen-induced conformational change of the glycoprotein IIb/IIIa complex in human platelet}

Triflavin is an Arg-Gly-Asp-containing antiplatelet peptide purified from Trimeresurus flavoviridis snake venom [21]. Triflavin inhibits platelet aggregation through direct interference with fibrinogen binding to the glycoprotein IIb/IIIa complex $\left(\alpha_{\text {IIb }} \beta_{3}\right.$ integrin) [28]. There is now a multitude of evidence suggesting that the binding of fibrinogen to the glycoprotein IIb/IIIa complex is the final common pathway for agonist-induced platelet aggregation. Therefore, we decided to further evaluate whether or not oxLDL binds directly to the platelet glycoprotein IIb/IIIa complex, leading to inhibition of platelet aggregation induced by agonists.

In this study, the relative intensity of fluorescence of FITC-triflavin $(2 \mu \mathrm{g} / \mathrm{ml})$ bound directly to collagen $(1 \mu \mathrm{g} / \mathrm{ml})$-activated platelets was about $321.0 \pm 9.6$ (Figure 2a), and it was markedly reduced in the presence of $5 \mathrm{mM}$ EDTA (negative control; 77.6 \pm 2.6 ) (Figure 2b). oxLDL (40 and $80 \mu \mathrm{g} / \mathrm{ml})$ did not significantly inhibit FITC-triflavin binding to the glycoprotein IIb/IIIa complex in platelet suspensions (Figure 2c, d), indicating that the mechanism of oxLDL's inhibitory effect on platelet aggregation does not involve binding to the glycoprotein IIb/IIIa complex.

\section{Effect of OxLDL on platelet membrane fluidity}

Platelet membrane fluidity was measured in DPHlabeled human platelets. Measurements using the fluorescent probe technique demonstrated that

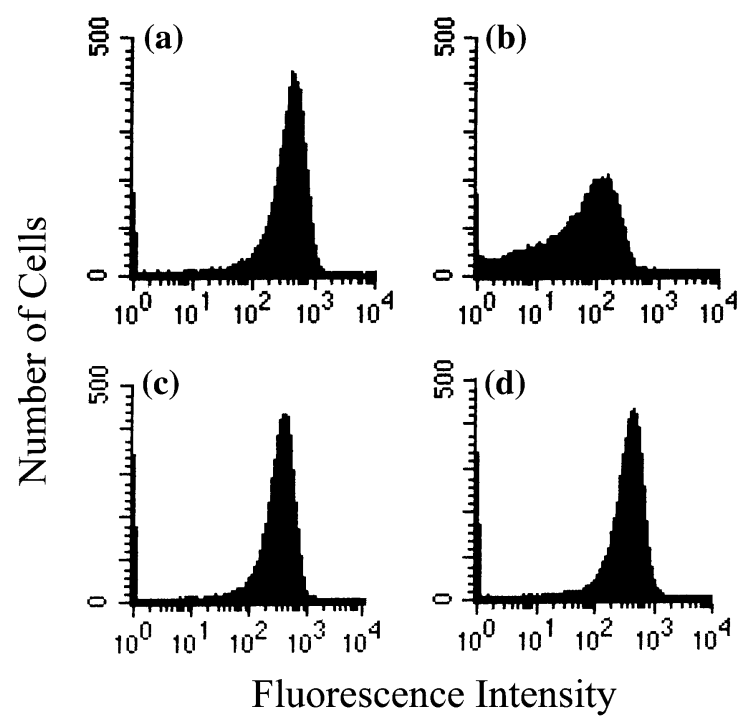

Figure 2. Flow cytometric analysis of FITC-triflavin binding to human platelets in the absence or presence of oxLDL. (a) The solid line represents the fluorescence profiles of FITC-triflavin $(2 \mu \mathrm{g} / \mathrm{ml})$ in the absence of oxLDL as a positive control; (b) in the presence of EDTA $(5 \mathrm{mM})$ as the negative control; or in the presence of oxLDL (c) $(40 \mu \mathrm{g} / \mathrm{ml})$ and (d) (80 $\mu \mathrm{g} / \mathrm{ml})$. Profiles are representative examples of four similar experiments.

oxLDL was capable of direct interaction with platelet membranes (Figure 3). Addition of oxLDL (40 and $80 \mu \mathrm{g} / \mathrm{ml}$ ) to the platelet preparations resulted in a concentration-dependent decrease in the DPH-relative fluorescence intensity. However, native LDL (nLDL) $(80 \mu \mathrm{g} / \mathrm{ml}) \mathrm{did}$ not significantly affect the platelet membrane fluidity (data not shown). This result implies that the inhibitory effect of oxLDL on platelet aggregation may be due, at least partly, to the results of its effects on platelet membrane fluidity.

\section{Effect of $O x L D L$ on PDBu-stimulated phosphorylation of the 47-kDa protein}

Stimulation of platelets with a number of different agonists, and PDBu in particular, induces activation of $\mathrm{PKC}$, which then phosphorylates proteins of $\mathrm{Mr} 40,000-47,000$ in addition to other proteins [29]. In this study, phosphorylation experiments were performed to examine the role of oxLDL in the activation of PKC in human platelets. When $\mathrm{PDBu}(150 \mathrm{nM})$ was added to human platelets prelabeled with ${ }^{32} \mathrm{PO}_{4}$ for $2 \mathrm{~min}$, a protein with an apparent $\mathrm{Mr}$ of 47,000 (P47) was predominately phosphorylated as compared with resting platelets 


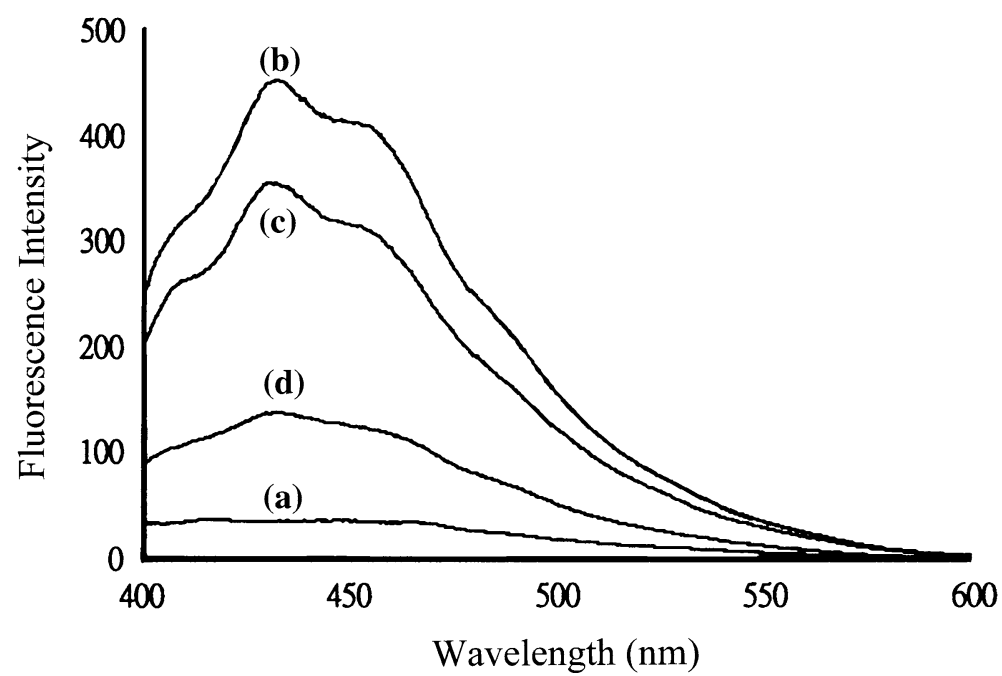

Figure 3. Fluorescence emission spectra of platelet membranes in the (a) absence or (b) presence of DPH (1 $\mu \mathrm{M})$. Curves C and D are the emission spectra of membranes labeled with DPH in the presence of oxLDL (c) $(40 \mu \mathrm{g} / \mathrm{ml})$ and (d) $(80 \mu \mathrm{g} / \mathrm{ml})$. Profiles are representative examples of four similar experiments.

(Figure $4 \mathrm{a}, \mathrm{b}$ ). oxLDL (40 and $80 \mu \mathrm{g} / \mathrm{ml}$ ) significantly inhibited the phosphorylation of P47 in this reaction. In this study, the extent of radioactivity in P47 was expressed as a relative detection density (PSL $/ \mathrm{mm}^{2}$; PSL, photostimulated luminescence) of the radioactive bands (Figure 4b). Moreover, oxLDL (40 and $80 \mu \mathrm{g} / \mathrm{ml}$ ) also significantly inhibited collagen $(1 \mu \mathrm{g} / \mathrm{ml})$-induced phosphorylation of P47 in human platelets (data not shown).

\section{Effect of OxLDL on VASP phosphorylation}

In our previous study [16], oxLDL (40 and $80 \mu \mathrm{g} /$ ml) significantly increased the level of cyclic AMP but not cyclic GMP in human platelets. It is presumed that cyclic AMP can induce VASP Ser ${ }^{157}$ phosphorylation in human platelets [25]. In this study, $\mathrm{PGE}_{1}(10 \mu \mathrm{M})$ and oxLDL $(40$ and $80 \mu \mathrm{g} / \mathrm{ml}$ ) markedly induced VASP Ser $^{157}$ phosphorylation compared with resting platelets (Figure 5). This result further demonstrates that oxLDL-inhibited platelet aggregation may be mediated through an increase in cyclic AMP formation.

Effect of OXLDL on thrombin-evoked pHi changes in platelets

Thrombin can trigger more-pronounced $\mathrm{pHi}$ changes than collagen in human platelets. Thus, we chose thrombin instead of collagen in this study. Figure 6 shows that the addition of thrombin $(1 \mathrm{U} /$ $\mathrm{ml})$ resulted in an increase in BCECF fluorescence equivalent to an increase in $\mathrm{pHi}$ values of about $0.302 \pm 0.058$ (Figure 6). This thrombin-evoked increase in pHi values was markedly inhibited in the presence of oxLDL (40 and $80 \mu \mathrm{g} / \mathrm{ml})$ (Figure 6). In addition, cariporide $(0.5 \mu \mathrm{M})$, a $\mathrm{Na}^{+} / \mathrm{H}^{+}$exchange inhibitor [30], significantly inhibited the thrombin-evoked pHi increase by about $90 \%$ in this study (data not shown).

\section{Discussion}

The principal objective of this study was to further describe the detailed inhibitory mechanisms involved in the inhibition of agonist-induced human platelet aggregation by oxLDL. This inhibitory effect of oxLDL was also demonstrable in the PRP. Although the action mechanisms of various platelet aggregation agonists, such as collagen and arachidonic acid, differ, oxLDL significantly inhibits platelet aggregation stimulated by all of them [16]. This implies that oxLDL may block a common step shared by these inducers. These results also indicate that the site of action of oxLDL is not at the receptor level of individual agonists. Triflavin acts by binding to the glycoprotein IIb/IIIa complex on the platelet 
(a)

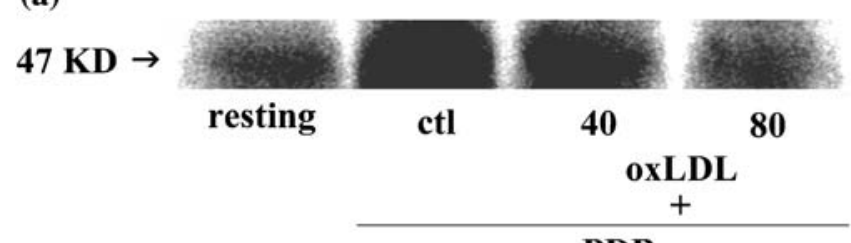

PDBu

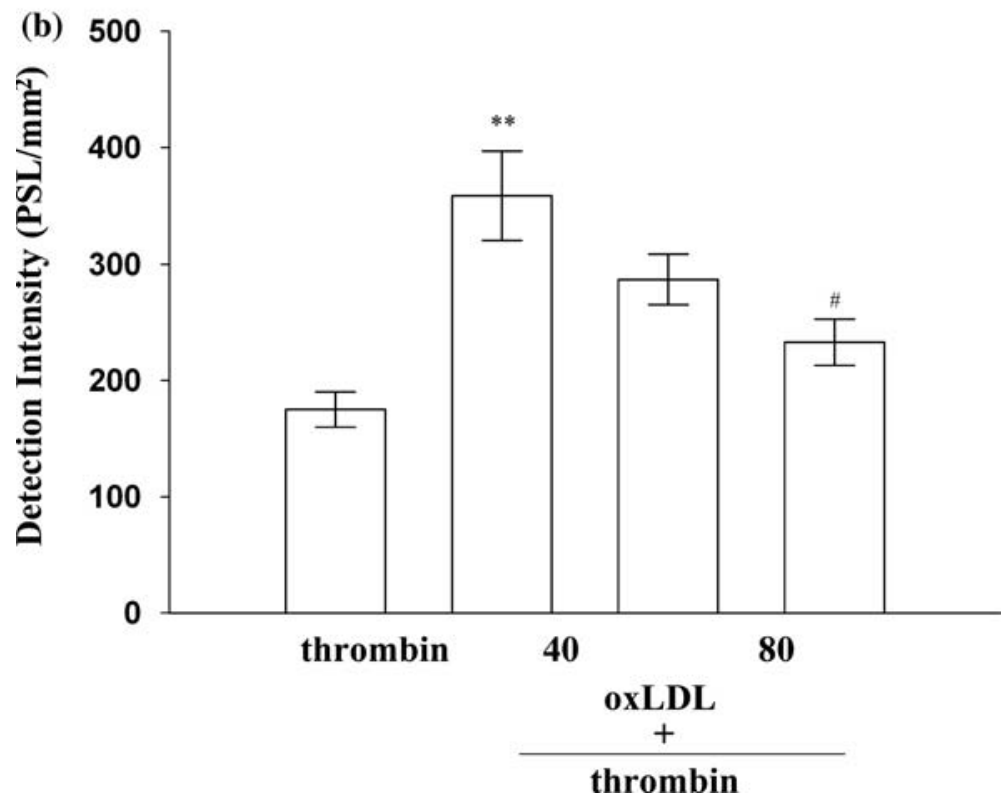

Figure 4. (a) Effect of oxLDL on phosphorylation of a protein of $M r 47,000$ (P47) in human platelets challenged with PDBu. Platelets were preincubated with oxLDL ( 40 and $80 \mu \mathrm{g} / \mathrm{ml}$ ) or isovolumetric solvent control (Tyrode's solution, ctl) followed by the addition of PDBu $(150 \mathrm{nM})$ to trigger protein kinase C activation. (a) Profiles are representative examples of four similar experiments. The arrow indicates a protein of $M r 47,000$ (P47). (b) The relative detection densities of the radioactive bands are expressed as PSL $/ \mathrm{mm}^{2}$ (PSL, photostimulated luminescence).

surface membrane, resulting in interference with the interaction of fibrinogen with its specific receptor $[21,28]$. In this study, we found that oxLDL did not significantly affect FITC-triflavin binding to the glycoprotein IIb/IIIa complex, indicating that the antiplatelet activity of oxLDL is possibly not directly due to interference with the binding of fibrinogen to its specific receptor on the platelet membrane. Furthermore, LOX-1 monoclonal antibody $(10 \mu \mathrm{g} / \mathrm{ml})$ (Anti-human LOX-1/ SR-E1 antibody, R\&D systems, Inc., Minneapolis, $\mathrm{MN}$ ) did not significantly reverse the inhibitory effect of oxLDL $(80 \mu \mathrm{g} / \mathrm{ml})$ in collagen $(1 \mu \mathrm{g} / \mathrm{ml})$ induced platelet aggregation (data not shown), indicating that the antiplatelet effect of oxLDL does not involve in LOX-1 receptor. Conformational changes in the plasma membrane and/or changes in membrane fluidity represent a generally

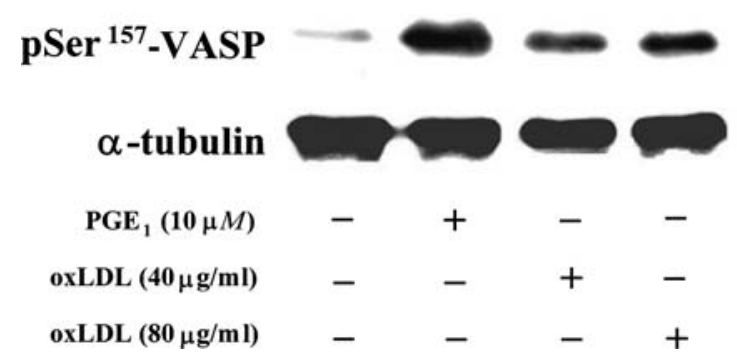

Figure 5. Effect of oxLDL on phosphorylation of VASP at $\mathrm{Ser}^{157}$ in human platelets. Platelets were incubated with prostaglandin $\mathrm{E}_{1}\left(\mathrm{PGE}_{1}\right)(10 \mu \mathrm{M})$ and oxLDL $(40$ and $80 \mu \mathrm{g} / \mathrm{ml})$, and solubilized directly in SDS-PAGE sample buffer. Phosphorylation of VASP at $\operatorname{Ser}^{157}$ was detected by immunoblotting with a monoclonal antibody specifically recognizing $\mathrm{Ser}^{157}$-phosphorylated VASP. Profiles are representative examples of four similar experiments. 
(a)
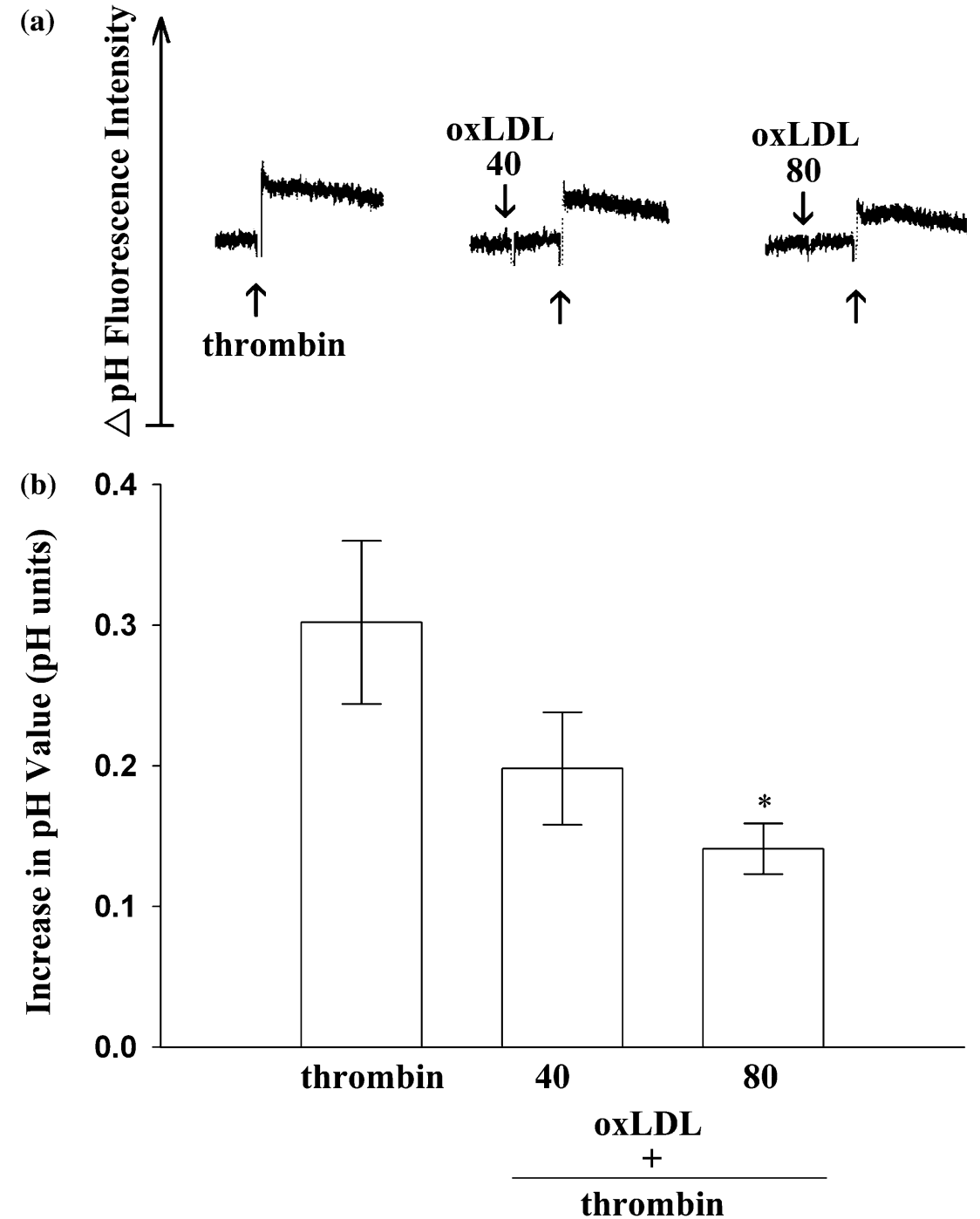

Figure 6. Effect of oxLDL on the thrombin-triggered intracellular $\mathrm{pH}$ increase in BCECF-AM-loaded platelets. Platelet suspensions $\left(4.5 \times 10^{8} / \mathrm{ml}\right)$ were preincubated with BCECF-AM $(5 \mu \mathrm{M})$, followed by the addition of thrombin $(1 \mathrm{U} / \mathrm{ml})$ to trigger intracellular alkalinization in the presence or absence of oxLDL $(40$ and $80 \mu \mathrm{g} / \mathrm{ml})$. Profiles are representative examples of four similar experiments.

accepted mechanism for the antiplatelet effect of numerous drugs, including local anesthetics, chlorpromazine, and beta-blockers [31]. Therefore, we wondered whether oxLDL might also inhibit platelet aggregation by influencing membrane fluidity. To test this hypothesis the fluorescent probe DPH was used to label biological membranes. In this study, oxLDL (40 and $80 \mu \mathrm{g} / \mathrm{ml}$ ) concentration-dependently decreased the DPH relative fluorescence intensity of platelet membranes (Figure 3). Activation of platelets is accompanied by a decrease in membrane fluidity as reflected by an increase in fluorescence intensity of DPH-labeled platelets [32]. Reorganization of cytoplasmic contractile and structural proteins is essential for platelet functions [32]. Therefore, a decrease in membrane fluidity (relatively rigid membrane) in activated platelets may affect the cytoskeletal network [32]. This finding suggests that changes in platelet membrane fluidity may be the primary mechanism responsible for the antiplatelet effect of oxLDL.

On the other hand, oxLDL significantly inhibits $\mathrm{PDBu}$-induced $\mathrm{PKC}$ activation. $\mathrm{PDBu}$ is known to 
intercalate with membrane phospholipids and form a complex with PKC translocated to the membrane [33]. Moreover, increased cyclic AMP formation can negatively affect agonist-induced PKC activation [34]. oxLDL increases the level of cyclic AMP [16] and cyclic AMP-induced VASP Ser ${ }^{157}$ phosphorylation in human platelets (Figure 5); therefore, the inhibitory effect of oxLDL in PDBuinduced $\mathrm{PKC}$ activation may be due, at least partly, to mediation of the increase in cyclic AMP formation. On the other hand, we also measured $\left[{ }^{3} \mathrm{H}\right]$ inositol monophosphate (IP) formation as an index of total inositol phosphate formation. The addition of collagen $(1 \mu \mathrm{g} / \mathrm{ml})$ resulted in a rise in IP formation of about 1.6-fold compared to that in resting platelets $[(1.6 \pm 0.3$ vs. $2.5 \pm 0.2)$ $\left.\times 10^{-4} \mathrm{cpm}\right](n=3$, data not shown). In the presence of oxLDL (40 and $80 \mu \mathrm{g} / \mathrm{ml}$ ), the radioactivity of IP formation in collagen-stimulated human platelets markedly inhibited about $25 \%$ and $29 \%$, respectively ( $n=3$, data not shown).

Activation of platelets by a variety of agonists (i.e., thrombin and ADP) is associated with stimulation of the $\mathrm{Na}^{+} / \mathrm{H}^{+}$exchanger [35]. This mode of activation of the $\mathrm{Na}^{+} / \mathrm{H}^{+}$exchanger usually induces a rise in cytosolic $\mathrm{Ca}^{2+}$, granule secretion, stimulation of shape change, and aggregation [35]. Basal pHi is normally maintained within a narrow range, and even small changes in pHi may have significant effects on platelet activity. In many cell types (i.e., smooth muscle cells), $\mathrm{Na}^{+} / \mathrm{H}^{+}$exchange activity is regulated by $\left[\mathrm{Ca}^{2+}\right] \mathrm{i}$ [36]. Furthermore, Kimura et al. [35] reported that cyclic nucleotides (i.e., cyclic AMP) modulate $\mathrm{Na}^{+} / \mathrm{H}^{+}$exchange in human platelets. Inhibition of $\mathrm{Na}^{+} / \mathrm{H}^{+}$exchange by cyclic AMP has also been demonstrated in other cells, such as epithelia of the urinary system and in osteoblast-like cells [37]. Thus, an agent (i.e., parathyroid hormone or dopamine) known to stimulate adenylate cyclase in these cells can also inhibit the $\mathrm{Na}^{+} / \mathrm{H}^{+}$ exchanger [37, 38]. Therefore, relationships among PKC activation, $\left[\mathrm{Ca}^{2+}\right]$ i, cyclic nucleotides (i.e., cyclic AMP), and the $\mathrm{Na}^{+} / \mathrm{H}^{+}$exchanger may play an important role in mediating the antiplatelet activity of oxLDL.

In conclusion, this study further suggests that the oxLDL may be due to induction of conformational changes in the platelet membrane, with a resulting influence on membrane fluidity followed by inhibition of PKC activation and subsequent inhibition of intracellular $\mathrm{Ca}^{2+}$ mobilization and phosphorylation of $\mathrm{P} 47$. In addition, oxLDL also triggers the formation of cyclic AMP and cyclic AMP-induced VASP $\operatorname{Ser}^{157}$ phosphorylation which subsequently inhibits the $\mathrm{Na}^{+} / \mathrm{H}^{+}$exchanger. This leads to reduced intracellular alkalinization, intracellular $\mathrm{Ca}^{2+}$ mobilization, and ultimately inhibition of platelet aggregation. The most important finding in this study provides new insights concerning the effects of oxLDL on platelet aggregation.

\section{Acknowledgements}

This study was sponsored by the National Science Council of Taiwan (NSC 93-2321-B-038-001) and Min-Sheng Healthcare (93MSH-TMU-15).

\section{References}

1. Steinberg D., Metabolism of lipoproteins and their role in the pathogenesis of atherosclerosis. Atheroscler. Rev. 18: $1-23,1988$.

2. Leeuwenburgh C., Hardy M.M., Hazen S.L., Wagner P., Oh-ishi S., Steinbrecher U.P. and Heinecke J.W., Reactive nitrogen intermediates promote low density lipoprotein oxidation in human atherosclerotic intima. J. Biol. Chem. 272: 1433-1436, 1997.

3. Berliner J.A. and Heinecke J.W., The role of oxidized lipoproteins in atherogenesis. Free Radic. Biol. Med. 20: 707-727, 1996.

4. Weksler B.B. and Nachman R.L., Platelets and atherosclerosis. Am. J. Med. 71: 331-333, 1981.

5. Tremoli E., Colli S., Maderna P., Baldassarre D. and Di M.G., Hypercholesterolemia and platelets. Semin. Thromb. Hemost. 19: 115-121, 1993.

6. Andrews H.E., Aitken J.W., Hassall D.G., Skinner V.O. and Bruckdorfer K.R., Intracellular mechanisms in the activation of human platelets by low-density lipoproteins. Biochem. J. 242: 559-564, 1987.

7. Ardlie N.G., Selley M.L. and Simons L.A., Platelet activation by oxidatively modified low density lipoproteins. Atherosclerosis 76: 117-124, 1989.

8. Katzman P.L., Bose R., Walker S., Perry Y. and Bolli P., Temperature-dependence of LDL binding and activation of human platelets. Thromb. Res. 64: 503-508, 1991.

9. Takahashi Y., Chiba H., Matsuno K., Akita H., Hui S.P., Nagasaka H., Nakamura H., Kobayashi K., Tandon N.N. and Jamieson G.A., Native lipoproteins inhibit platelet activation induced by oxidized lipoproteins. Biochem. Biophys. Res. Commun. 222: 453-458, 1996.

10. Block L.H., Knorr M., Vogt E., Locher R., Vetter W., Groscurth P., Qiao B.Y., Pometta D., James R. and Regenass M., Low density lipoprotein causes general cellular activation with increased phosphatidyl inositol 
turnover and lipoprotein catabolism. Proc. Natl. Acad. Sci. USA 85: 885-889, 1998.

11. Weidtmann A., Scheithe R., Hrboticky N., Pietsch A., Lorenz R. and Siess W., Mildly oxidized LDL induces platelets aggregation through activation of phospholipase $\mathrm{A}_{2}$. Arterioscler. Thromb. Vasc. Biol. 15: 1131-1138, 1995.

12. Katzman P.L., Bose R., Henry S., McLean D.L., Walker S., Fyfe C., Perry Y., Mymin D. and Bolli P., Serum lipid profile determines platelet reactivity to native and modified LDL-cholesterol in humans. Thromb. Haemost. 71: 627632, 1994.

13. Pedreno J., de Castellarnau C., Cullare C., Ortin R., Sanchez J.L., Llopart R. and Gonzalez-Sastre F., Platelet receptor recognizes with same apparent affinity both oxidative and native LDL. Arterioscler. Thromb. Vasc. Biol. 14: 401-408, 1994.

14. Vlasova I.I., Azizova O.A. and Lopukhin Y.M., Inhibitor analysis of LDL induced platelet aggregation. Biochemistry (Moscow) 62: 307-311, 1997.

15. Vlasova I.I., The effect of oxidatively modified low-density lipoproteins on platelet aggregability and membrane fluidity. Platelets 11: 406-414, 2000.

16. Chou D.S., Hsiao G., Shen M.Y., Fong T.H., Lin C.H., Chen T.F. and Sheu J.R., Low concentration of oxidized low-density lipoprotein suppresses platelet reactivity in vitro: an intracellular study. Lipids 39: 433-440, 2004.

17. Sheu J.R., Lee C.R., Lin C.H., Hsiao G., Ko W.C., Chen Y.C. and Yen M.H., Mechanisms involved in the antiplatelet activity of Staphylococcus aureus lipoteichoic acid in human platelets. Thromb. Haemost. 83: 777-784, 2000.

18. Dousset N., Ferretti G., Taus M., Valdiguie P. and Curatola G., Fluorescence analysis of lipoprotein peroxidation. Meth. Enzymol. 233: 459-469, 1994.

19. Sheu J.R., Lee C.R., Hsiao G., Hung W.C., Lee Y.M., Chen Y.C. and Yen M.H., Comparison of the relative activities of $\alpha$-tocopherol and PMC on platelet aggregation and antioxidative activity. Life Sci. 65: 197-206, 1999.

20. Steinbrecher U.P., Oxidation of human low-density lipoprotein results in derivatization of lysine residues of apolipoprotein B by lipid peroxide decomposition products. J. Biol. Chem. 262: 3603-3608, 1987.

21. Sheu J.R., Lin C.H., Peng C.H. and Huang T.F., Triflavin, an Arg-Gly-Asp-containing peptide, inhibits the adhesion of tumor cells to matrix protein via binding to multiple integrin receptors expressed on human hepatoma cells. Proc. Soc. Exp. Biol. Med. 213: 71-79, 1996.

22. Kitagawa S., Shinohara T. and Kametani F., Effects of alcohols on ADP-induced aggregation and membrane fluidity of gel-filtered bovine blood platelets. J. Membrane Biol. 79: 97-102, 1984.

23. Wroblewski F. and Ladue J.S., Lactic dehydrogenase activity in blood. Proc. Soc. Exp. Biol. Med. 90: 210-215, 1955.

24. Grabarek J., Raychowdhury M., Ravid K., Kent K.C., Newman P.J. and Ware J.A., Identification and functional characterization of protein kinase $\mathrm{C}$ isozymes in platelets and HEL cells. J. Biol. Chem. 267: 10011-10017, 1992.

25. Li Z., Ajdic J., Eigenthaler M. and Du X., A predominant role for cAMP-dependent protein kinase in the cGMPinduced phosphorylation of vasodilator-stimulated phosphoprotein and platelet inhibition in humans. Blood 101: 4423-4429, 2003.

26. Sweatt J.D., Johnson S.L., Cargoe E.J. and Limbird L.E., Inhibition of $\mathrm{Na}^{+} / \mathrm{H}^{+}$exchange block stimulus-provoked arachidonic acid release in human platelets. J. Biol. Chem. 260: 12910-12919, 1985.

27. Horne W.C., Norman N.E., Schwartz D.B. and Simons E.R., Changes in cytoplasmic $\mathrm{pH}$ and in membrane potential in thrombin-stimulated platelets. Eur. J. Biochem. 120: 295-302, 1981.

28. Sheu J.R., Teng C.M. and Huang T.F., Triflavin, an RGDcontaining antiplatelet peptide, binds to GP IIIa of ADPstimulated platelets. Biochem. Biophys. Res. Commun. 189: 1236-1242, 1992.

29. Siess W. and Lapetina E.G., Platelet aggregation induced by alpha 2-adrenoceptor and protein kinase $\mathrm{C}$ activation. $\mathrm{A}$ novel synergism. Biochem. J. 263: 377-385, 1989.

30. Baumgarth M., Beier N. and Gericke R., Bicyclic acylguanidine $\mathrm{Na}^{+} / \mathrm{H}^{+}$antiporter inhibitors. J. Med. Chem. 41: 3736-3747, 1998

31. Kobayashi T., Yamada J., Setaka M. and Kwan T., Effects of chlorpromazine and other calmodulin antagonists on phosphatidylcholine-induced vesiculation of platelet plasma membranes. Biochim. Biophys. Acta 855: 5862, 1986.

32. Pribluda V. and Rotman A., Dynamics of membranecytoskeleton interactions in activated blood platelets. Biochemistry 21: 2825-2832, 1982.

33. Kraft A.S. and Anderson W.B., Phorbol esters increase the amount of $\mathrm{Ca}^{2+}$, phospholipid-dependent protein kinase associated with plasma membrane. Nature 301: 621-623, 1983.

34. Walter U., Eigenthaler M., Geiger J. and Reinhard M., Role of cyclic nucleotide-dependent protein kinases and their common substrate VASP in the regulation of human platelets. Adv. Exp. Med. Biol. 344: 237-249, 1993.

35. Kimura M., Lasker N. and Avir A., Cyclic nucleotides attenuate thrombin-evoked alterations in parameters of platelet $\mathrm{Na} / \mathrm{H}$ antiport. The role of cytosolic $\mathrm{Ca}^{2+}$. J. Clin. Invest. 89: 1121-1127, 1992.

36. Nieuwland R., Van Willigen G. and Akkerman J.N., Different pathways for control of $\mathrm{Na}^{+} / \mathrm{H}^{+}$exchange via activation of the thrombin receptor. Biochem. J. 297: 4752, 1994.

37. Felder C.C., Campbell T., Albrecht F. and Jose P.A., Dopamine inhibits $\mathrm{Na}^{+}-\mathrm{H}^{+}$exchanger activity in renal BBMW by stimulation of adenylate cyclase. Am. J. Physiol. 259: F297-F303, 1990.

38. Reid I.R., Civitelli R., Avioli L.V. and Hruska K.A., Parathyroid hormone depresses cytosolic $\mathrm{pH}$ and DNA synthesis in osteoblast-like cells. Am. J. Physiol. 255: E9E15, 1988. 